\title{
Implementasi Model Pembelajaran Argumentasi Dialogis dalam Pembelajaran Fisika untuk Meningkatkan Kemampuan Argumentasi Ilmiah Siswa SMA
}

\author{
Muslima) \\ Universitas Pendidikan Indonesia, Jl. Dr. Setiabudhi No. 229 Bandung 40154 \\ Email: ${ }^{a}$ mus_upi@yahoo.co.id
}

\begin{abstract}
Low ability of scientific arguments related to the students' learning process in the physics classroom that has not habituate scientific argumentation ability. This study aimed to examine the effect of the implementation of arguments dialogical learning model to increase students' ability of scientific argumentation. Argumentation dialogical learning model consists of five phases of learning, namely stages: (1) identification of the problem; (2) group argument discussion; (3) classroom argument discussion; (4) class mediation; and (5) the integration of knowledge. Each stage involves students learning activities directly in order to develop the ability of scientific argumentation. The pre-experimental method with the one group pretest and posttest design used in this research. The essay ability of the scientific arguments test and observation sheet used as a research instruments. Subjects in this study were students of $10^{\text {th }}$ grade in one of the state senior high schools in Bandung, which is determined by random cluster sampling technique. The results show there is an increase in the ability of the student to the acquisition of scientific arguments with medium category after argument dialogical learning model implemented and it was concluded that the implementation of arguments dialogical learning model increased the students' ability of scientific argumentation.
\end{abstract}

Keywords: argument dialogic learning model, scientific argumentation ability

\begin{abstract}
Abstrak
Rendahnya kemampuan argumentasi ilmiah siswa terkait proses pembelajaran fisika di kelas yang belum melatihkan kemampuan argumentasi ilmiah. Penelitian ini bertujuan melihat pengaruh implementasi model pembelajaran argumentasi dialogis terhadap kemampuan argumentasi ilmiah siswa. Model pembelajaran argumentasi dialogis terdiri dari lima tahap pembelajaran, yaitu: (1) identifikasi masalah; (2) diskusi argumentasi kelompok; (3) diskusi argumentasi kelas; (4) mediasi kelas; dan (5) integrasi pengetahuan. Setiap tahapan melibatkan secara langsung aktivitas siswa untuk berlatih mengembangkan kemampuan argumentasi ilmiah. Metode penelitian yang digunakan adalah pre-experiment dengan desain penelitian one group pretest and posttest. Instrumen penelitian yang digunakan meliputi tes kemampuan argumentasi ilmiah berbentuk uraian dan lembar observasi. Subyek dalam penelitian ini adalah siswa kelas X pada salah satu SMA Negeri di Kota Bandung yang ditentukan dengan teknik cluster random sampling. Hasil penelitian menunjukkan peningkatan kemampuan argumentasi ilmiah siswa dengan kategori sedang setelah diimplementasikan model pembelajaran argumentasi dialogis, sehingga dapat disimpulkan bahwa implementasi model pembelajaran argumentasi dialogis berpengaruh terhadap kemampuan argumentasi ilmiah siswa.
\end{abstract}

Kata-kata kunci: model pembelajaran argumentasi dialogis, kemampuan argumentasi ilmiah 


\section{PENDAHULUAN}

Fisika merupakan salah satu mata pelajaran yang mengkaji dan meneliti setiap peristiwa yang terjadi di alam secara sistematis, serta berupaya untuk menelusuri hukum-hukum atau prinsip-prinsip yang berlaku di dalamnya. Fakta-fakta kehidupan seperti gerak, cahaya, optik, kalor, listrik, magnet, dan materi lain yang sehari-hari digunakan manusia dipelajari dalam fisika. Fisika memberikan pelajaran yang baik kepada manusia untuk hidup selaras berdasarkan hukum alam (BSNP, 2006). Fisika membuka kesempatan bagi manusia untuk memahami lingkungan di mana mereka tinggal dengan menggunakan metode ilmiah, menyelidiki, mengetahui apa yang belum diketahui, menjelaskan mengapa sesuatu dapat terjadi, serta berupaya menyelesaikan masalah dalam kehidupan sehari-hari. Melalui cara-cara seperti ini, fisika telah menjadi ilmu pengetahuan alam (IPA) yang mendasari penemuan di berbagai bidang sehingga memicu perkembangan pesat di bidang teknologi, informasi, dan komunikasi (Celik, et al., 2013). Oleh karena itu, perlu adanya peningkatan kualitas pendidikan fisika di sekolah untuk membentuk manusia yang memiliki daya nalar dan daya pikir yang tinggi, kreatif, mampu memecahkan masalah dan mengomunikasikan gagasan-gagasannya. Pendidikan fisika harus dapat membantu siswa menyongsong masa depan yang lebih baik. Fisika sebagai mata pelajaran yang menjadi tulang punggung teknologi memiliki alasan tersendiri untuk dipelajari oleh siswa di tingkat SMA. Proses pembelajaran fisika di SMA seyogianya dapat diarahkan pada pemberian pengalaman belajar untuk mengembangkan sejumlah kompetensi agar peserta didik menjelajahi dan memahami alam sekitar secara ilmiah.

Argumentasi memiliki peran penting dalam kegiatan pembelajaran fisika karena memberikan kesempatan kepada siswa untuk terlibat dalam diskusi kelompok dan saling memberikan pendapat yang menunjukkan sejauh mana pemahaman konsep, keterampilan, dan kemampuan penalaran ilmiah (Osborne, 2010). Melalui proses argumentasi, siswa belajar fisika sekaligus mempunyai kesempatan untuk mempraktikkan metode ilmiah ketika mempertahankan atau menyangkal ide-ide (Demircioglu dan Ucar, 2012). Argumentasi adalah proses memperkuat suatu klaim melalui analisis berpikir kritis berdasarkan dukungan dengan bukti-bukti dan alasan yang logis (Inch \& Warnick, 2006). Melalui kegiatan argumentasi di kelas, siswa terlibat dalam memberikan bukti, data, serta teori yang valid untuk mendukung pendapat (klaim) terhadap suatu permasalahan.Toulmin (Robertshaw dan Campbell, 2013) mengajukan skema yang mendeskripsikan struktur suatu argumentasi yang dikenal sebagai Toulmin's Argumen Pattern (TAP). Kemampuan argumentasi ilmiah ditunjukkan oleh komponen-komponen utama dalam TAP yaitu kemampuan siswa dalam memberikan pendapat (claim), memberikan dan menganalisis data, memberikan pembenaran (warrant), memberikan dukungan (backing), dan membuat sanggahan (rebuttal) terhadap permasalahan. Argumentasi mendapatkan perhatian khusus dalam penelitian pendidikan (Acar dan Patton, 2012; Demirbag dan Gunel, 2014; Demircioglu dan Ucar, 2012; Diwu, 2010; Erduran, et al, 2006; Robertshaw dan Campbell, 2013) karena sejak zaman dulu para ilmuwan menggunakan argumen untuk membangun teori, model dan penjelasan tentang setiap peristiwa yang terjadi di alam. Munculnya bukti-bukti baru dalam ilmu pengetahuan alam mendorong ilmuwan untuk mempertimbangkan kembali teori yang selama ini telah dipahami. Perkembangan berbagai masalah sosio-ilmiah (socio-scientific) di masyarakat jaman sekarang mengisyaratkan agar siswa dituntut untuk memiliki kemampuan berargumentasi secara ilmiah (Robertshaw dan Campbell, 2013). Setiap pendapat yang dikemukakan harus didasari dengan data, alasan pembenaran dan bukti ilmiah yang kuat sehingga klaim dapat diterima. Berdasarkan hal tersebut, maka pembelajaran fisika di SMA perlu melatih siswa dengan kemampuan argumentasi ilmiah.

Model pembelajaran yang dikembangkan untuk melatih kemampuan argumentasi ilmiah siswa adalah model pembelajaran argumentasi dialogis (Diwu, 2010). Dalam model ini siswa berdialog secara argumentatif berdasarkan Toulmin's Argumen Pattern (TAP). Siswa mengembangkan sendiri pola argumentasi mulai dari membuat klaim, mengumpulkan dan menganalisis data, membuat pembenaran (warrant) dan membuat dukungan (backing) untuk memperkuat klaim. Sintaks model meliputi 5 Tahap, yaitu: (1) identifikasi masalah; (2) diskusi argumentasi kelompok; (3) diskusi argumentasi kelas; (4) mediasi kelas; dan (5) integrasi pengetahuan. Model pembelajaran argumentasi dialogis menyediakan kesempatan yang luas kepada siswa untuk berdebat, membuat klaim atau klaim kontra yang didukung dengan bukti-bukti untuk mempertahankan sikap mereka atau

e-Jurnal: http://doi.org/10.21009/1 
bahkan menimbulkan sanggahan untuk membatalkan klaim tersebut. Dalam hal ini, guru lebih berperan sebagai fasilitator dari pada sebagai pemasok ilmu pengetahuan bagi siswa. Pada akhir pembelajaran, dihasilkan kesimpulan tentang topik permasalahan yang dikemukakan. Dengan begitu, siswa mampu mengekspresikan pandangan secara bebas, mengeksternalisasi pikiran, menghapus keraguan, dan bahkan mengubah pikiran apabila keliru (Diwu, 2010).

\section{METODE}

Metode penelitian yang digunakan dalam penelitian ini adalah pre-experiment dengan desain penelitian one group pretest and posttest. Instrumen penelitian yang digunakan meliputi tes kemampuan argumentasi ilmiah berbentuk uraian dan lembar observasi. Subyek dalam penelitian ini adalah siswa kelas X pada salah satu SMA Negeri di Kota Bandung yang ditentukan dengan teknik cluster random sampling. Peningkatan kemampuan argumentasi ilmiah siswa pada penelitian ini dibatasi pada perubahan nilai tes kemampuan argumentasi ilmiah siswa sebelum dan sesudah pembelajaran berdasarkan rata-rata gain yang dinormalisasi $(\langle\mathrm{g}\rangle)$ pada materi fluida statik. Untuk mengetahui apakah model pembelajaran argumentasi dialogis terlaksana sepenuhnya atau tidak oleh guru dan siswa selama proses pembelajaran berlangsung dicari dengan menghitung persentase keterlaksanaan model pembelajaran argumentasi dialogis secara keseluruhan.

\section{HASIL DAN PEMBAHASAN}

Hasil observasi keterlaksanaan model pembelajaran argumentasi dialogis melalui aktivitas guru dan aktivitas siswa disajikan pada TABEL 1 .

TABEL 1. Rekapitulasi persentase keterlaksanaan model pembelajaran argumentasi dialogis melalui aktivitas guru dan aktivitas siswa

\begin{tabular}{|c|c|c|c|c|c|c|c|}
\hline \multirow{3}{*}{ No } & \multirow{3}{*}{ Tahap } & \multicolumn{6}{|c|}{ Persentase (\%) Keterlaksanaan Pembelajaran } \\
\hline & & \multicolumn{3}{|c|}{ Aktivitas Guru } & \multicolumn{3}{|c|}{ Aktivitas Siswa } \\
\hline & & $\mathbf{P - 1}$ & $\mathbf{P}-\mathbf{2}$ & $\mathbf{P}-3$ & $\mathbf{P - 1}$ & $\mathbf{P}-\mathbf{2}$ & $\mathbf{P}-\mathbf{3}$ \\
\hline 1 & Identifikasi masalah & 83 & 100 & 100 & 100 & 100 & 100 \\
\hline 2 & $\begin{array}{l}\text { Diskusi argumentasi } \\
\text { kelompok }\end{array}$ & 83 & 100 & 100 & 83 & 100 & 100 \\
\hline 3 & Diskusi argumentasi kelas & 83 & 83 & 100 & 83 & 100 & 100 \\
\hline 4 & Mediasi kelas & 100 & 100 & 100 & 67 & 83 & 83 \\
\hline 5 & Integrasi pengetahuan & 100 & 100 & 100 & 83 & 100 & 100 \\
\hline \multicolumn{2}{|c|}{ Rata-rata persentase (\%) } & 89,8 & 96,6 & 100 & 84,2 & 96,6 & 96,6 \\
\hline \multicolumn{2}{|c|}{ Kriteria } & \multicolumn{3}{|c|}{$\begin{array}{l}\text { Hampir seluruh aktivitas } \\
\text { terlaksana }\end{array}$} & \multicolumn{3}{|c|}{$\begin{array}{l}\text { Hampir seluruh aktivitas } \\
\text { terlaksana }\end{array}$} \\
\hline
\end{tabular}

Pada TABEL 1 terlihat bahwa baik aktivitas guru maupun aktivitas siswa pada pelaksanaan model pembelajaran argumentasi dialogis untuk pertemuan pertama, kedua, dan ketiga masing-masing pada materi pembelajaran tekanan hidrostatis, hukum Pascal dan hukum Archimedes, serta tegangan permukaan terlaksana dengan perolehan persentase keterlaksanaan pembelajaran (KP) mencapai $75 \% \leq \mathrm{KP}<100 \%$ dengan kriteria hampir seluruh aktivitas pembelajaran terlaksana. Tidak meratanya pencapaian keterlaksanaan pembelajaran melalui aktivitas siswa boleh jadi karena pada pertemuam pertama siswa belum terbiasa dengan pembelajaran melalui model pembelajaran argumentasi dialogis yang diterapkan. Namun demikian dengan semakin intensifnya pemberian aktivitas berargumentasi, maka pada pertemuan terakhir siswa sudah terbiasa dengan pembelajaran yang diterapkan. Dengan demikian dapat dikatakan bahwa guru mampu melaksanakan setiap tahapan model pembelajaran argumentasi dialogis dengan baik dalam melatihkan kemampuan argumentasi ilmiah pada siswa.

Model pembelajaran argumentasi dialogis mengajak siswa untuk berdialog secara argumentatif berdasarkan Toulmin's Argumen Pattern (TAP) sebagai landasan teori yang digunakan. Pada tahap 
identifikasi masalah, guru menyajikan situasi atau peristiwa yang berkaitan dengan topik permasalahan yang akan didiskusikan. Pada tahap ini juga, siswa diberi lembar kerja sesuai dengan prosedur dalam TAP. Lembar kerja ini berisi pertanyaan dan tugas individu untuk mengajukan klaim, memberikan data atau bukti mengapa ia mengajukan klaim seperti itu, serta alasan yang membenarkan data. Sumber argumen harus dituliskan pada lembar kerja. Pada tahap diskusi argumentasi kelompok, guru membagi siswa ke dalam beberapa kelompok kecil. Setiap anggota kelompok melakukan diskusi argumentatif tentang klaim masing-masing disertai bukti, data dan berbagai alasannya. Argumen terbaik hasil kesepakatan masing-masing kelompok ditulis ulang dan dipersiapkan untuk dipresentasikan di dalam kelas. Tahap diskusi argumentasi kelas, guru memberi kesempatan kepada perwakilan setiap kelompok untuk mempresentasikan argumen kelompoknya masing-masing. Siswa dari kelompok lain dapat menanggapi, mendukung atau bahkan menyanggah argumen apabila terjadi perbedaan klaim disertai bukti dan alasan yang kuat. Tahap mediasi kelas, guru mengumpulkan argumen setiap kelompok dan membahas bersama-sama tentang kelebihan dan kekurangannya. Guru mengarahkan diskusi siswa pada pembahasan argumen secara menyeluruh dan memfokuskan analisis pada pusat permasalahan yang mengandung kontroversi. Pada tahap ini, diperoleh argumen akhir yang merupakan kesepakatan seluruh kelas. Pada tahap integrasi pengetahuan, guru mengajak siswa berdiskusi secara reflektif dan menyeluruh, bertujuan untuk memadukan setiap informasi yang diperoleh dikaitkan dengan materi yang dipelajari. Guru juga membahas materi-materi yang berkaitan dengan permasalahan. Pada tahap terakhir ini, guru bersama siswa mengambil kesimpulan bersama tentang hasil pembelajaran.

Peningkatan kemampuan argumentasi ilmiah siswa setelah diimplementasikan model pembelajaran argumentasi dialogis disajikan pada TABEL 2.

TABEL 2. Rekapitulasi rerata skor tes awal dan tes akhir kemampuan argumentasi lmiah siswa

\begin{tabular}{ccc}
\hline \multicolumn{2}{c}{ Rerata skor } & $\langle$ g $\rangle$ \\
\hline $\begin{array}{c}\text { Tes Awal } \\
\text { 32,1 }\end{array}$ & Tes Akhir & 0,69 \\
& Kriteria & Sedang \\
\hline
\end{tabular}

Berdasarkan TABEL 2, terlihat bahwa rerata skor tes akhir siswa lebih besar dari rerata skor tes awal siswa. Dengan demikian dapat dikatakan bahwa terjadi peningkatan kemampuan argumentasi ilmiah siswa. Besar peningkatannya terlihat dari perolehan nilai rata-rata gain yang dinormalisasi $\langle\mathrm{g}\rangle$ sebesar 0,69 termasuk kategori sedang mendekati tinggi. Tercapainya peningkatan kemampuan argumentasi ilmiah siswa tidak terlepas dari intervensi model pembelajaran argumentasi dialogis yang memberi ruang kepada siswa untuk melakukan aktivitas argumentasi ilmiah secara interaktif. Siswa belajar secara produktif bagaimana mengkonstruksi argumentasi ilmiah berdasarkan permasalahan dari materi fisika yang dipelajari. Temuan penelitian ini menguatkan hasil penelitian Chen \& She (2012) yang menemukan bahwa kemampuan argumentasi ilmiah siswa yang memperoleh pembelajaran fisika berbasis argumentasi lebih baik daripada siswa yang memperoleh pembelajaran konvensional. Melalui proses argumentasi, siswa belajar membangun sendiri pemahaman atau pengetahuan terhadap sains (scientific knowledge) dari data atau bukti yang mereka peroleh sendiri dan pemahaman mengenai fenomena sains (scientific explanation) serta mampu mengemukakannya dalam bentuk argumentasi ilmiah (Diwu, 2010; Demircioglu dan Ucar, 2012). Melalui cara ini siswa mampu memahami masalah, menyelesaikan masalah dengan informasi yang tersedia dengan mengembangkan klaim untuk menjawab permasalahan, menyertakan dan menganalisis data untuk mendukung klaim, menjelaskan hubungan antara data dan klaim sebagai pembenaran (warrant), dan melandasi pembenaran berupa dukungan (backing) untuk mendukung klaim. Temuan ini konsisten dengan hasil penelitian (McNeill et al, 2006) yang mengungkapkan bahwa pengembangan argumentasi dalam pembelajaran sains berdasarkan pola argumentasi Toulmin dapat menumbuhkan kemampuan berargumentasi siswa.

Peningkatan tiap aspek kemampuan argumentasi ilmiah siswa setelah diimplementasikan model pembelajaran argumentasi dialogis disajikan pada GAMBAR 1. 


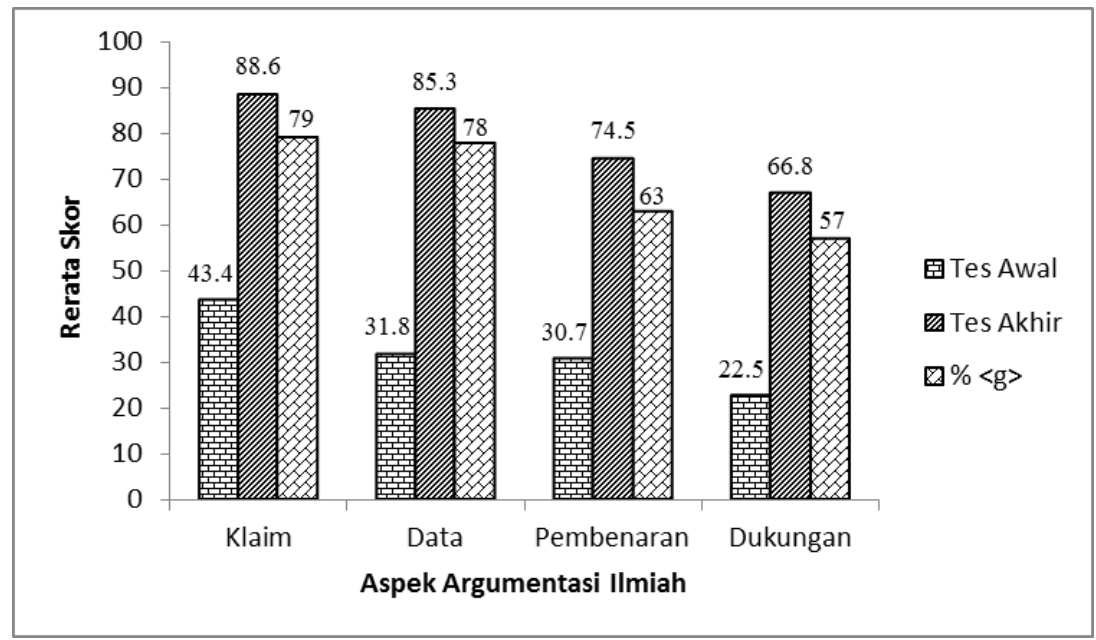

GAMBAR 1. Diagram peningkatan tiap aspek kemampuan argumentasi ilmiah siswa

Pada GAMBAR 1 terlihat bahwa perolehan rerata skor pada tes akhir lebih tinggi dari rerata skor pada tes awal untuk semua aspek kemampuan argumentasi ilmiah. Terjadi peningkatan kemampuan membuat klaim yang akurat sesuai dengan permasalahan, menyertakan dan menganalisis data untuk mendukung klaim, menjelaskan hubungan antara data dan klaim berupa pembenaran (warrant), dan melandasi pembenaran untuk mendukung klaim berupa dukungan (backing). Hal ini menunjukkan bahwa model pembelajaran argumentasi dialogis dapat meningkatkan semua aspek kemampuan argumentasi ilmiah siswa.

Berdasarkan pola argumentasi yang dikonstruksi siswa, ditemukan bahwa klaim yang dibuat siswa ada yang akurat, ada juga yang tidak akurat. Osborne et al (2004) memandang bahwa klaim yang tidak akurat bisa jadi karena tidak didukung oleh data yang diberikan, seperti yang dikemukakannya bahwa "...claim are justified by relating them to the data on which they are based". Ketika klaim yang dibuat siswa tidak akurat dalam arti tidak didukung oleh data, siswa tidak mesti mengubah klaim awal terhadap permasalahan. Akan tetapi dapat dijadikan sebuah refleksi pada diri siswa bahwa tidak setiap klaim terhadap sebuah permasalahan akan selalu benar, namun memerlukan data untuk membuktikan kebenarannya. Kemampuan siswa dalam menganalisis data ada yang sepenuhnya mendukung klaim, ada juga yang hanya sebagian dapat mendukung klaim. Namun demikian, secara keseluruhan siswa sudah mampu untuk menyertakan dan menganalisis data dengan benar. Osborne et al (2004) menyatakan bahwa data sangat penting dalam argumentasi karena data akan dijadikan bukti untuk mendukung atau menolak klaim. Argumentasi memerlukan kejelasan dan keyakinan dengan perantaraan data yang benar. Dengan data yang benar, siswa dapat merangkaikan suatu penuturan yang logis melalui pembenaran (warrant) menuju kepada suatu kesimpulan yang dapat dipertanggungjawabkan atau menuju klaim yang dapat diterima (Keraf, 1981). Dalam menuliskan pembenaran (warrant), mahasiswa sebenarnya hanya perlu menjelaskan hubungan data dan klaim, seperti yang dikemukankan Driver et al (2000) bahwa "warrant is the reasoning that connects the data to the claim". Kemampuan siswa dalam membuat dukungan (backing) untuk melandasi pembenaran ada yang sepenuhnya mendukung klaim, ada juga yang hanya sebagian yang mendukung klaim. Dukungan dapat berupa teori yang mendasari permasalahan. Oleh karena itu penting bagi siswa untuk memahami materi ajar fisika dengan baik agar bisa membuat dukungan (backing) yang dapat melandasi pembenaran (warrant) untuk mendukung klaim yang akurat. Sebagian siswa masih belum bisa memberikan dukungan (backing) yang ditopang oleh pemahaman konsep fisika yang kuat yang berkaitan langsung dengan permasalahan untuk melandasi pembenaran (warrant).

\section{PENUTUP}

Implementasi model pembelajaran argumentasi dialogis dalam pembelajaran fisika dapat meningkatkan kemampuan argumentasi ilmiah siswa SMA. Peningkatan terjadi pula untuk semua aspek kemampuan argumentasi ilmiah yang meliputi kemampuan membuat klaim yang akurat sesuai 
dengan permasalahan, menyertakan dan menganalisis data untuk mendukung klaim, menjelaskan hubungan antara data dan klaim berupa pembenaran (warrant), dan melandasi pembenaran untuk mendukung klaim berupa dukungan (backing).

\section{UCAPAN TERIMAKASIH}

Penulis mengucapkan terima kasih kepada Bapak Andi Suhandi atas diskusinya yang bermanfaat.

\section{REFERENSI}

Acar, O. \& Patton, B.R 2012, 'Argumentation and Formal Reasoning Skills in An ArgumentationBased Guided Inquiry Course'. Procedia-Social and Behavioral Sciences, vol. 46, p. 4756-4760.

BSNP, 2006, 'Standar Isi Kurikulum 2006 Mata Pelajaran Fisika SMA/MA', Jakarta.

Celik P., Onder F., \& Silay, I, 2013, 'The Effects of Problem Based Learning on the Student's Success in Physics Course', Procedia-Social and Behavioral Sciences vol. 28, p. 656-660.

Chen, C.H., \& She, H.C 2012, 'The Impact of Recurrent On-line Synchronous Scientific Argumentation on Students' Argumentation and Conceptual Change', Educational Technology \& Society. vol.15. no. 1, p.197-210.

Demirbag, M. \& Gunel, M 2014, 'Integrating Argument-Based Science Inquiry with Modal Representations: Impact on Science Achievement, Argumentation, and Writing Skills'. Educational Sciences: Theory and Practice, vol. 14, no.1, p.386-391.

Demircioglu, T \& Ucar, S 2012, 'The Effect of Argument-Driven Inquiry on Pre-Service Science Teacher's Attitudes and Argumentation Skills'. Procedia-Social and Behavioral Sciences, vol. 4, p. 5035-5039.

Diwu, C 2010, 'Effects of a Dialogical Argumentation Instructional Model on Grade 10 Learners' Conception of Fermentation'. PRASEA.

Erduran, S., Ardac, D. \& Guzel B.Y 2006, 'Learning to Teach Argumentation: Case Studies of PreService Secondary Science Teachers'. Eurasia Journal of Mathematics, Science and Technology Education, vol. 2, no. 2, p.1-13.

Driver, R., Newton, P., \& Osborne, J 2000. 'Establishing the norms of scientific argumentation in classrooms'. Science Education.

Inch, E. S., \& Warnick, B 2006, 'Critical Thinking and Communication (5th Ed.). Boston: Allyn \& Bacon.

Keraf, G 1981, Argumentasi dan Narasi. Jakarta: Gramedia Pustaka Utama.

McNeill, K. L., Lizotte, D. J., \& Krajcik, J 2006, 'Supporting Students' Construction of Scientific Explanations by Fading Scaffolds in Instructional Materials', The Journal of the Learning Sciences. vol.15, no.2, p. 153-191.

Osborne, J., Erduran, S., \& Simon, S 2004, 'Enhancing The Quality of Argumentation in School Science', Journal of Research in Science Teaching, vol 41, no.10, p. 994-1020.

Osborne, J 2010, 'Arguing to Learn in Science': "The Role of Collaborative, Critical Discourse. American Association for the Advancement of Science", 1200 New York Avenue, Washington, DC 20005.

Robertshaw, B. \& Campbell, T 2013, ' Constructing Arguments: Investigating Pre-Service Science Teacher's Argumentation Skills in a Socio-Scientific Context', Science Education International Journal, vol. 24, Issue 2, p.195-211. 